\title{
Examining human rights and mental health among women in drug abuse treatment centers in Afghanistan
}

This article was published in the following Dove Press journal:

International Journal of Women's Health

2 April 2012

Number of times this article has been viewed

\section{Melissa Harris Abadi' \\ Stephen R Shamblen' \\ Knowlton Johnson' \\ Kirsten Thompson' \\ Linda Young' \\ Matthew Courser ${ }^{1}$ \\ Jude Vanderhoff' \\ Thom Browne ${ }^{2}$}

'Pacific Institute for Research and Evaluation - Louisville Center, Louisville, KY, USA; ${ }^{2}$ United States Department of State, Bureau of International Narcotics and Law Enforcement, Washington, DC, USA

Correspondence: Melissa Harris Abadi Pacific Institute for Research and Evaluation, Inc. - Louisville Center, 1300 S Fourth Street, Ste 300, Louisville, KY 40208, USA

Tel +I 5026343694

Fax + I 5026345690

Email mharris@pire.org

\begin{abstract}
Denial of human rights, gender disparities, and living in a war zone can be associated with severe depression and poor social functioning, especially for female drug abusers. This study of Afghan women in drug abuse treatment (DAT) centers assesses (a) the extent to which these women have experienced human rights violations and mental health problems prior to entering the DAT centers, and (b) whether there are specific risk factors for human rights violations among this population. A total of 176 in-person interviews were conducted with female patients admitted to three drug abuse treatment centers in Afghanistan in 2010. Nearly all women (91\%) reported limitations with social functioning. Further, $41 \%$ of the women indicated they had suicide ideation and $27 \%$ of the women had attempted suicide at least once 30 days prior to entering the DAT centers due to feelings of sadness or hopelessness. Half of the women (50\%) experienced at least one human rights violation in the past year prior to entering the DAT centers. Risk factors for human rights violations among this population include marital status, ethnicity, literacy, employment status, entering treatment based on one's own desire, limited social functioning, and suicide attempts. Conclusions stemming from the results are discussed.
\end{abstract}

Keywords: Afghanistan, women, human rights, mental health, drug abuse treatment

\section{Introduction}

Due to its long history of war, Afghanistan has endured extreme poverty, lack of employment, a large refugee population, extreme division of social class, inadequate educational infrastructure, horrific violence, and millions of civilian casualties since 1979. ${ }^{1-5}$ While living in a war-torn country takes its toll on the entire population, the situation in Afghanistan is especially harsh on Afghan women, as they are often considered unequal to their male counterparts and in many cases are subsequently abused, denied education, health care, employment, and other basic human rights. ${ }^{6,7}$

Denial of human rights, gender inequality, and living in a war zone have been linked with severe depression and poor social functioning..$^{7-9}$ Research has shown that such mental health problems are often present among female drug abusers. ${ }^{10,11}$ Further, because Afghanistan is a major source of the global supply of opium and hashish, ${ }^{12}$ and because opium is commonly used by Afghans for medicinal purposes, ${ }^{12,13}$ Afghan women face a unique and significant reality in which they have easier access to illegal and psychotropic drugs than they do to drug abuse treatment, education, or health care.

While studies have begun to look at this important issue by reporting prevalence of human rights violations and mental health problems among Afghan women, ${ }^{6-9}$ this study builds on prior research by assessing the prevalence of these issues among women 
with serious substance use problems in drug abuse treatment (DAT) centers in Afghanistan, and examining risk factors for human rights violations among this population.

\section{Women's human rights in Afghanistan}

The United Nations (UN) Universal Declaration of Human Rights states that everyone is entitled to the rights set forth in the declaration "without distinction of any kind, such as race, color, sex, language, religion, political or other opinion, national or social origin, property, birth, or other status." And, those rights include: the right to not be subjected to torture, degrading, or inhumane treatment; the right to move about freely within your own country; the right to education and work; the right to marry only with full consent of both parties; and the right to a standard of living for the health and well-being of oneself and family. ${ }^{14} \mathrm{~A} U \mathrm{UN}$ report on the challenges of human rights and cultural diversity further states, "The right to culture is limited at the point at which it infringes on another human right. No right can be used at the expense or destruction of another, in accordance with international law." 15 The rights set forth in the UN declaration helped guide this study and were referenced when developing survey instruments in order to adequately assess the human rights violations experienced by Afghan women.

The plight of Afghan women became a highly publicized international concern after the Taliban takeover, which imposed extreme gender-based restrictions on women's human rights punishable by harassment, torture, and death. Although Afghanistan has been characteristically a patriarchal society due to religious and cultural beliefs, as well as the societal structure, Taliban rule brought violent enforcement of laws which were more restrictive and oppressive than traditional life was for Afghan women. ${ }^{16}$ Rasekh and colleagues $^{7}$ found that during this time women reported poor access $(77 \%)$ or no access $(20 \%)$ to health care services, occasions in which they were ill and unable to seek medical care (53\%), extreme fear when in public (39\%), and extreme restricted social activities $(68 \%)$.

\section{Human rights violations and mental health problems}

The harsh realities of living in Afghanistan, including severe gender-based inequalities and human rights violations, have been linked to serious mental health problems among Afghan women. ${ }^{8,9}$ For instance, Rasekh and colleagues ${ }^{7}$ reported that when Afghan women were asked about the 2 years post-Taliban occupation, most reported a decline in physical
(71\%) and mental health status (81\%), and a decline in access to health care $(62 \%)$. Many women reported symptoms of posttraumatic stress disorder (42\%), major depression (97\%), and significant anxiety (86\%).

Amowitz et $\mathrm{al}^{8}$ found that the majority (70\%) of Afghan women in their study from Taliban controlled areas attributed their mental health problems to Taliban official policies toward women. Results showed that severe depression was far more prevalent among Afghan women exposed to Taliban policies $(78 \%)$ than those living in non-Taliban controlled areas $(28 \%)$. There were also higher occurrences of suicide ideation (65\% vs $18 \%$ ) and suicide attempts (16\% vs $9 \%$ ), and a higher number of those in Taliban controlled areas indicated that the Taliban contributed "quite a bit" or "extremely" to their suicide ideation or attempts ( $22 \%$ vs $2 \%)$.

Four years after the Taliban rule officially came to an end, Cardozo et $\mathrm{al}^{9}$ reported results which showed that Afghan women, when compared to Afghan men, were still suffering from poor mental health, including greater symptoms of depression ( $73 \%$ vs 59\%), anxiety ( $84 \%$ vs 59\%), posttraumatic stress disorder (48\% vs 32\%), and lower social functioning $(\mathrm{M}=2.77$ vs 3.92). Most of the sample (62\%) had experienced four or more traumatic events, and the most commonly reported traumatic events for females included denial of basic human rights such as no access to health care (54\%), lack of food and water (52\%), and lack of shelter (46\%).

\section{The current study}

The results of these studies allude to the potential impact that human rights violations have on Afghan women. Although Taliban rule officially ended in late 2001, the aftermath of its influence is still present in Afghanistan. The effects of intense trauma experienced by Afghan women will subsist for far longer, especially because many of them have turned to substance use in an effort to cope with feelings of depression and hopelessness, to ease pain, and cope with repressive lifestyles. ${ }^{12,13}$ Although documented estimates are believed to be low, in 2005 it was estimated that $2 \%$ of all Afghan women $(120,000)$ were addicted to drugs. ${ }^{17}$

Research shows that women with a history of emotional, physical, and sexual abuse are more likely to engage in substance use as a coping mechanism. ${ }^{13,18,19}$ Maguet and Majeed ${ }^{20}$ posit that addiction is a direct consequence of physical and psychological violence related to conflict-affected countries. In order to better understand the challenges and problems faced by drug-addicted Afghan women, this study examines (a) the extent to which women in DAT have experienced human rights 
violations and mental health problems prior to entering the DAT centers, and (b) whether there are specific risk factors for human rights violations among these women. The following research questions guided this study:

Q1: To what extent have Afghan women entering DAT centers experienced human rights violations? What types of human rights violations have they experienced?

Q2: To what extent do Afghan women entering DAT centers report mental health problems (social functioning, suicide ideation, and suicide attempts)?

Q3: What individual characteristics are risk factors for human rights violations among Afghan women entering DAT centers?

Q4: What mental health problems are risk factors for human rights violations among Afghan women entering DAT centers?

\section{Research methods Research setting}

Due to the significant problem of drug abuse in Afghanistan, the Bureau of International Narcotics and Law Enforcement Affairs, United States Department of State funded the Colombo Plan Drug Advisory Programme to provide training to directors and staff of DAT centers in Afghanistan. The Pacific Institute for Research and Evaluation (PIRE) was hired to assess the implementation of this training and the centers' subsequent treatment success. A total of seven DAT centers were selected by the Bureau of International Narcotics and Law Enforcement Affairs for the evaluation. The current paper utilizes data from three of these DAT centers that are for women and their children only. At the time this study began, these centers were located in provinces considered to be in the "safe zone" of the country and thus least likely to have been disrupted by the ongoing war. It should be noted, however, that there have been reported conflicts in these areas within the past 2 years. The names and locations of these DAT centers are confidential.

\section{Study participants}

A total of 176 in-person interviews were conducted with female participants between $0-5$ days after completing their detoxification process in the DAT centers. One-hundred seventy-two cases were used for analyses after removing four cases that provided more than one inconsistent response, which is a common quality assurance standard in large national datasets (Monitoring the Future investigators, written communication, December 2007).

\section{Measures}

\section{Human rights violations}

Participants responded yes or no when asked whether they had experienced 10 different human rights violations prior to entering the DAT centers. The authors developed these items, based on numerous online news reports, ${ }^{21,22}$ the UN's Universal Declaration of Human Rights, ${ }^{14,15}$ research articles, ${ }^{6-8}$ and consultation with an expert panel of four Afghan DAT center directors. Whereas we do not claim this list is exhaustive, the expert panel felt it was representative of the types of human rights violations most commonly experienced by Afghan women.

To better understand various types of human rights violations, we conducted a principal component analysis (sometimes referred to as exploratory factor analysis) with varimax rotations on the ten items. According to Pedhazur and Schmelkin, ${ }^{23}$ principal component analysis attempts to characterize the majority of the variability in all items with smaller groupings of items, while factor analysis attempts to group items into scales based on those items with the strongest interrelationships. Computationally, the only difference is distinguished by whether the diagonal elements in the correlation matrix analyzed are set to one (ie, principal component analysis, which assumes all variance is explained) or whether the communalities (ie, the variance explained in other items by a particular item) are used as the matrix diagonal.

We examined two-, three-, and four-component solutions based on eigenvalues greater than one $(2.91,1.80,1.26$, and 1.05). We chose a three-component solution, as it was the most substantively interpretable solution and adding a fourth component resulted only in a one-item component that only accounted for an additional $11 \%$ of the variance. The first component accounted for $29 \%$ of the variance in the data and the five items (denied food as punishment, threatened with denial of food or shelter by husband/family, forced to live in social isolation, forced to consume drugs, and forced to work in poppy cultivation) were grouped together and termed Maltreatment. The scale had acceptable internal consistency reliability ( $\alpha=0.68$ ), and component loadings ranged between 0.83 and 0.31 . The second component accounted for $18 \%$ of the variance and the three items (forbidden to drive a car, denied education, and forbidden to go out in public without a male relative) represented activities that we termed Gender-based Inequality. This scale also had acceptable internal consistency reliability $(\alpha=0.73)$, and component loadings ranged between 0.82 and 0.78 .

The final component accounted for $13 \%$ of the variance and the two items (physical abuse and sexual assault) represented 
severe forms of abuse, and had an acceptable internal consistency reliability ( $\alpha=0.74)$, and component loadings ranged between 0.91 and 0.89 . We ultimately calculated scale scores as an occurrence of any of the behaviors comprising the scale (ie, a dichotomous scale score), as the distributions of the items were heavily left-censored. As a summary measure, we also examined the occurrence of any of the ten human rights violations. Considering the occurrence of all ten behaviors, alpha was still acceptable $(\alpha=0.66)$.

\section{Mental health factors}

Social functioning measures the extent to which physical and emotional health interferes with or limits normal social activities. Four items (developed by Hays et $\mathrm{al}^{24}$ ) measured the extent and frequency that participants experienced these physical and emotional problems 30 days prior to entering treatment (eg, To what extent did your physical health or emotional problems interfere with your normal social activities with your family, friends, neighbors, or groups?) on two scales, 0 (not at all) to 3 (quite a bit) and 0 (never) to 3 (all the time). The four scale items were internally consistent $(\alpha=0.69)$. Suicide ideation measures the extent to which the participants had suicidal thoughts 30 days prior to treatment using a single item adapted from Lung and Lee (2008). ${ }^{25}$ Participants responded on a 0 (not at all) to 4 (extremely) scale. Suicide attempts was also measured by asking participants if they had attempted suicide (yes/no) 30 days prior to entering treatment.

\section{Substance use}

In order to determine the frequency and types of drugs being used among this population, participants were asked how often they used 14 substances in the past 6 months and past 30 days prior to entering treatment. As one goal is to examine the prevalence of substance use among the women in these DAT centers, all items were dichotomized to use (1) or no use (0). Here, we focused only on opium, hashish, heroin, and "crystal" (a potent form of heroin). (The additional substances included in the questionnaire were used by less than $2 \%$ of the sample in the past 6 months). Alcohol use was nearly nonexistent in this population with only one participant reporting drinking three out of 30 days prior to entering treatment. This low prevalence of alcohol use is likely because alcohol use is strictly against religious and government law and highly stigmatized.

\section{Individual characteristics}

Participants indicated their age (ie, date of birth, which is estimated, because Afghans do not typically keep track of their age), marital status ( single, married, separated, divorced, widowed), ethnicity (Pashtun, Tajik, Uzbek, Turkmen, Hazara, Baloch, Kirghiz, Nuristani, Aimak, Arab), living situation prior to treatment (with spouse, with other family), and whether they had children. Participants indicated whether they were literate, their level of education (no school, primary school, secondary school, high school/vocational training, college, or higher), whether they were employed 6 months prior to entering treatment, and whether they had experienced a loss of a close family member due to war/conflict within the last 2 years. Participants rated 18 reasons for entering treatment using a 0 (not important at all) to 3 (very important) scale (eg, "Your family wanted you to go.").

\section{Data collection}

PIRE partnered with D3 Systems, Inc, a social and market research company based in Washington DC, and the Afghan Center for Socio-Economic and Opinion Research (ACSOR) in Afghanistan to collect the data for this study. ACSOR was founded in 2003 by D3 Systems and is a registered market and opinion research agency in Afghanistan with trained Afghan researchers and interviewers. ACSOR interviewers for this study included trained medical students residing in Afghanistan. An in-person structured interview that included questions previously validated in other treatment outcome studies was developed by PIRE, and carefully reviewed by ACSOR field staff and an expert panel of four Afghan DAT center directors or associate directors. Revisions were made to clarify meanings and to ensure cultural appropriateness of phrasing and terminology. The final instrument was translated into Pashto and Dari (the primary languages of our sample) and back-translated by ACSOR field managers to ensure linguistic equivalency. The translated instrument was also reviewed independently by two bilingual Afghan nationals contracted by PIRE.

Data used in this paper are drawn from the in-person baseline structured interviews that were conducted with female patients in three Afghan DAT centers by ACSOR trained female interviewers from February 2010 to September 2010. Consent forms and interview questions were read aloud by the ACSOR interviewers to the patients due to low literacy levels. Patients were provided with a consent form that was read aloud to describe the study, procedures, risks, and safeguards. Patients first consented to the release of their names and admission dates to the research team, and then to participate in the study. Patients were informed that their participation was voluntary and that their decision on whether to participate would not result in 
any penalties or benefits to them or to the centers. Patients were informed that their responses would be confidential and that they could decline to answer any questions. If the patient signed the consent form, the baseline interview was conducted at that time in a private room in the DAT centers to ensure confidentiality. The interviews took about 1 hour to complete. Participants were given a US\$5 incentive for completing the interview.

\section{Data analyses}

Simple percentages and means were calculated to address research questions one and two. For research question two, we rounded scale scores to the nearest integer, such that they could be interpreted according to the actual response scale labels in the questionnaire. Inferential analysis examined relationships with human rights violations for research questions three and four. Research question three was answered by examining the relationship between individual characteristics and human rights violations using logistic regression. The two individual characteristics that were not dichotomous (age and education) were split at the median response to yield 40 years of age and younger versus over 40 years old, and no education versus some education. All four measures of human rights violations (gender-based inequality, maltreatment, abuse, and "any") were regressed on all of the individual characteristics in four analyses. Research question four was answered by examining the relationship of mental health problems and human rights violations using logistic regression. We regressed all four measures of human rights violations on all mental health factors.

\section{Results}

\section{Individual characteristics}

Of the 172 female participants with usable data, the mean age was 39 years with a range of 18-70 years. Participants were mainly Turkmen (30\%), Pashtun (29\%), Tajik (21\%), or Hazara $(12 \%)$. Seventy-two percent of participants were married, $15 \%$ were widowed, and $11 \%$ were single. Of those who were married, $96 \%$ of married participants had an arranged marriage, while $11 \%$ reported being forced to marry someone they did not want to marry. Most of the sample had children (70\%), and, of those, the average number of children was two per participant with an average of two children living with them at the DAT centers. Before entering the DAT centers, $52 \%$ of participants lived with family and $45 \%$ lived with their spouse. The majority $(88 \%)$ did not have any formal schooling. Most of them could not read before entering the DAT centers (91\%). Most participants (86\%) had not been employed 6 months prior to entering the centers. Thirteen percent had lost a close family member in the past 2 years due to war.

When given a list of 18 reasons for entering the DAT center, 63\% said that family (including their spouse) wanting them to go into treatment was "very important." Other reasons considered "very important" were: "You decided for yourself that you wanted treatment" (50\%); "You had medical or physical problems" (45\%); "Your friends wanted you to go" (44\%); and "Spouse or family was shamed/stigmatized by drug addiction" (27\%).

The most commonly abused substances by participants were opium, crystal, hashish, and heroin (see Table 1). A total of $91 \%$ had used one or more of these four substances in the 6 months prior to entering treatment, while $88 \%$ had used one or more substances 30 days prior to entering treatment. Some participants reported no use in the past 6 months $(8 \%)$ or past 30 days $(10 \%)$, which is likely due to some participants trying to stop using drugs while on a waiting list prior to entering treatment. The most abused substance by participants was opium with $68 \%$ using in the 6 months before treatment and $66 \%$ using in the 30 days before treatment. The second most abused substance by participants was "crystal" (a potent form of heroin) with $28 \%$ of participants using in the past 6 months and $22 \%$ using in the past 30 days. These four substances account for the majority of substance use reported by these participants. Only three participants $(2 \%)$ reported using other drugs asked about on the questionnaire (including hallucinogens, cocaine, sosigan, mandrax and heroin, other opiates, methamphetamines, other amphetamines, tranquilizers, barbiturates, other sedatives, or other substances) in the past 6 months and the past 30 days.

Table I Participants using substances in the past 6 months and 30 days

\begin{tabular}{|c|c|c|c|c|c|c|}
\hline & \multicolumn{3}{|c|}{ Past 6 month use } & \multicolumn{3}{|c|}{ Past 30 day use } \\
\hline & n using & $\%$ using & $\mathbf{n}$ & n using & $\%$ using & $\mathbf{n}$ \\
\hline Opium & 117 & $68 \%$ & 172 & 113 & $66 \%$ & 172 \\
\hline Crystal & 46 & 28 & 166 & 37 & 22 & 166 \\
\hline Heroin & II & 7 & 168 & 10 & 6 & 168 \\
\hline Hashish & 3 & 2 & 172 & 2 & I & 172 \\
\hline $\begin{array}{l}\text { Opium, crystal, } \\
\text { heroin, or hashish }\end{array}$ & 156 & 91 & 172 & $|5|$ & 88 & 172 \\
\hline $\begin{array}{l}\text { Only other } \\
\text { substances }^{\mathrm{a}}\end{array}$ & 3 & 2 & 172 & 3 & 2 & 172 \\
\hline No substance use & 13 & 8 & 172 & 18 & 10 & 172 \\
\hline Total & 172 & 100.00 & 172 & 172 & 100.00 & 172 \\
\hline
\end{tabular}

Note: a"Other" substances include hallucinogens, cocaine, sosigan, mandrax and heroin, other opiates, methamphetamines, other amphetamines, tranquilizers, barbiturates, other sedatives, and other substances. 


\section{Research question one: extent of human rights violations}

Considering base rates, $50 \%$ of participants reported experiencing at least one form of human rights violations prior to entering the DAT centers; $35 \%$ reported gender-based inequality, $36 \%$ reported maltreatment, and $4 \%$ reported abuse (see Table 2). We realize that $4 \%$ is an extremely low base rate, so all correlations listed for abuse must be interpreted with extreme caution. We felt it was necessary to keep abuse in the analyses since physical and sexual abuse are issues Afghan women often face, but rarely self-report due to various reasons such as stigmatization and cultural norms. ${ }^{12}$

\section{Research question two: extent of mental health problems}

As Table 3 shows, almost the entire sample (91\%) of women entering the DAT centers experienced some limitations with social functioning (ie, the extent to which physical and emotional health prevented them from engaging in normal social activities) 30 days prior to entering the centers, when defining "slightly/rarely" through "quite a bit/all the time" responses as having limited social functioning. Additionally, a large proportion of the sample (41\%) had experienced some suicidal ideation 30 days prior to entering the centers, when defining "rarely" through "extreme" responses as having had suicidal thoughts. Additionally, 27\% of participants attempted suicide at least once 30 days prior to entering the centers due to feelings of sadness or hopelessness.

Table 2 Participants experiencing human rights violations

\begin{tabular}{|c|c|c|c|}
\hline & $\begin{array}{l}n \\
\text { experiencing }\end{array}$ & $\begin{array}{l}\% \\
\text { experiencing }\end{array}$ & $\mathbf{n}$ \\
\hline Any human rights violation & 86 & $50 \%$ & 172 \\
\hline Maltreatment & 61 & 36 & 172 \\
\hline Denied food as punishment & 32 & 19 & 168 \\
\hline $\begin{array}{l}\text { Threatened with denial } \\
\text { of food or shelter by } \\
\text { husband/family }\end{array}$ & 28 & 17 & 169 \\
\hline $\begin{array}{l}\text { Forced to live in } \\
\text { social isolation }\end{array}$ & 17 & 10 & 170 \\
\hline Forced to consume drugs & 32 & 19 & 168 \\
\hline $\begin{array}{l}\text { Forced to work in poppy } \\
\text { cultivation }\end{array}$ & 9 & 5 & 172 \\
\hline Gender-based inequality & 59 & 35 & 171 \\
\hline Forbidden to drive a car & 22 & 14 & 159 \\
\hline Denied education & 39 & 24 & 165 \\
\hline $\begin{array}{l}\text { Forbidden to go out in } \\
\text { public without a male } \\
\text { relative }\end{array}$ & 43 & 25 & 169 \\
\hline Abuse & 7 & 4 & 172 \\
\hline Physical abuse & 6 & 3 & 172 \\
\hline Sexual assault & 4 & 2 & 172 \\
\hline
\end{tabular}

\section{Research question three: individual characteristics as risk factors for human rights violations}

As can be seen in Table 4, women who were married ( $38 \%$ vs $29 \%$ ) were 5.08 times more likely to report indicators of maltreatment, and women of Pashtun ethnicity (62\% vs $45 \%$ ) were 5.80 times more likely to experience at least one of the human rights violations about which we asked. Women who were literate ( $80 \%$ vs $47 \%$ ) were 14.74 times more likely to report at least one of the human rights violations about which we asked. Women who were employed were 4.76 times (inverse of odds ratio $[\mathrm{OR}]=0.21$ ) less likely to report gender-based inequality ( $17 \%$ vs $37 \%$ ). Women who entered DAT because of their own desire were 2.30 times more likely to report being victims of maltreatment ( $43 \%$ vs $28 \%$ ), 3.34 times more likely to report gender-based inequality (44\% vs $26 \%$ ), and 2.91 times more likely to report at least one human rights violation ( $58 \%$ vs $42 \%$ ).

\section{Research question four: mental health problems as risk factors for human rights violations}

Women reporting limited social functioning were more likely to report all forms of human rights violations prior to entering the DAT centers, except gender-based inequality (maltreatment [OR $=2.36]$, abuse [OR $=12.24]$, and also having experienced any of the ten human rights violations $[\mathrm{OR}=1.72]$ ). Suicide ideation was not a significant risk factor for human rights violations, but women attempting suicide were more likely to have experienced all forms of human rights violations (gender-based inequality $[\mathrm{OR}=2.80$, $P=0.06]$, maltreatment [OR $=5.74]$, abuse $[\mathrm{OR}=26.05]$, and having experienced any of the ten human rights violations $[\mathrm{OR}=3.99])($ see Table 5).

\section{Discussion}

\section{Profile of women entering drug abuse treatment}

The majority of women in the DAT centers had not received formal schooling, could not read, and had not been employed. This is consistent with the profile of a typical female Afghan drug user who has even less education and is more than twice as likely to not have a job than other females. ${ }^{12}$ Lack of education and employment among Afghan females is also due to the fact that they are expected (sometimes forced) to marry young, typically around the age of 15 years old, and are pressured to have children immediately. ${ }^{26}$ Most women in 
Table 3 Participants' mental health problems

\begin{tabular}{llllll}
\hline & \multicolumn{5}{c}{ Percentages for rounded scale scores } \\
\cline { 2 - 6 } & $\mathbf{0}$ & I & $\mathbf{2}$ & $\mathbf{3}$ & $\mathbf{4}$ \\
\hline Social functioning $(0-3)^{\mathrm{a}}$ & $10 \%$ & $16 \%$ & $56 \%$ & $19 \%$ & \\
Suicide ideation $(0-4)^{\mathrm{b}}$ & 59 & 13 & 10 & 6 & 12 \\
Suicide attempt $(0-1)^{\mathrm{c}}$ & 73 & 27 & & & \\
\hline
\end{tabular}

Notes: ${ }^{\text {a }}$ = strongly agree, 2 = agree, $3=$ disagree, $4=$ strongly disagree; ${ }^{a} 0=$ not at all/never, I = slightly/rarely, 2 = moderately/sometimes, 3 = quite a bit/all the time; ${ }^{\mathrm{b}} 0=$ not at all, $\mathrm{I}=$ slightly, 2 = moderately, 3 = quite a bit, $4=$ extremely; ${ }^{\circ} 0=$ no, $\mathrm{I}=$ yes.

our sample reported an "arranged" marriage, while a smaller number reported being "forced" to marry someone they did not want to marry.

The most commonly abused substances by women entering the DAT centers were opium, crystal, hashish, and heroin. Most of the study participants had used one or more of these substances 30 days prior to treatment. Our results are similar to those reported by the United Nations Office on Drug Use and Crime, ${ }^{12}$ which found that Afghan citizens are increasingly dependent on cannabis, opium, heroin, opioids, and tranquilizers and suffering severe mental, physical, and social problems as a result of their addiction.

\section{Human rights violations}

Half of the women in our sample experienced at least one type of human rights violation prior to entering the DAT centers. About one-third of these women experienced some form of maltreatment, including denial of food or shelter, forced to live in social isolation, forced to consume drugs, and forced to work in poppy cultivation. This is consistent with findings from similar studies that indicate "lack of food and water" is an extremely traumatic event, ${ }^{9}$ social isolation is an ongoing problem, ${ }^{7}$ and husbands sometimes force their wives to consume drugs to keep them from fighting back or from leaving. ${ }^{13}$ While other research has not reported the rates of women being forced to work in poppy cultivation, news reports indicate this is a reality for some Afghan women. ${ }^{27,28}$

About one-third of the women experienced gender-based inequality prior to entering the DAT centers, including being forbidden to go in public without a male relative, forbidden to drive a car, and denied education. These findings are not surprising given the strict enforcement of laws forbidding females to attend school or work outside the home. ${ }^{3}$ Although the Taliban regime has ended, some maintain that women's rights have yet to be restored to pre-Taliban traditions, ${ }^{16,26}$ and the majority of females are still not attending school. ${ }^{29}$

Physical and sexual abuse violations had a relatively low base-rate phenomenon with a very small percentage of women reporting these types of abuse prior to entering the DAT centers. This is consistent with other reports finding this to be a rare - and likely underreported - event. ${ }^{12}$ In an attempt to address the issue of underreporting, a 2008 United Nations Office on Drugs and Crime (UNODC) study ${ }^{30}$ asked Afghan women whether they knew any women who were addicted to drugs and had been raped, and $54 \%$ said yes. This suggests that sexual abuse does occur among this population but that it is not reported due to stigma or shame. Alternatively, it is also possible that some women may not feel this type of behavior is a violation of their rights, but rather a tolerated behavior between husband and wife in Afghan society. ${ }^{31}$ As evidence of this, a law was passed in 2009 permitting "marital rape" in Afghanistan. ${ }^{32}$

\section{Mental health problems}

Most of the women in this sample reported limited social functioning, which is likely due to the fact that women are denied rights and freedoms that would encourage social functioning, such as walking freely in public, going to school and work, and talking openly in social settings. ${ }^{33}$ Many of the women had experienced suicide ideation before entering the centers, which is common among this population. ${ }^{8}$ And, nearly one-third of the women (27\%) had attempted suicide 30 days prior to entering the DAT centers, which is a higher percentage than those reported from a sample of Afghan women in Taliban controlled areas (16\%) and non-Taliban controlled areas $(9 \%){ }^{8}$ Further, this percentage is extremely high when compared to the worldwide rate of suicide attempts. ${ }^{34}$

\section{Risk factors for human rights violations}

Married women were more likely to report maltreatment prior to entering the DAT centers. This is consistent with research that indicates that human rights violations among Afghan women are inflicted mostly by husbands. ${ }^{3,13,35}$ Also, women of Pashtun ethnicity were more likely to have experienced at least one form of human rights violation prior to entering the DAT centers, which follows research that indicates that Pashtun communities still impose Taliban-like conditions where women are treated dishonorably and denied basic rights. ${ }^{36}$

Women who reported being able to read also reported greater human rights violations prior to entering the DAT centers, which might be explained by the fact that more educated Afghan women are more aware of their basic rights and thus more likely to report violations. ${ }^{37}$ Employed women were less likely to have experienced gender-based inequality, which is likely because women who are working outside the home have fewer social restrictions conferred upon them. 


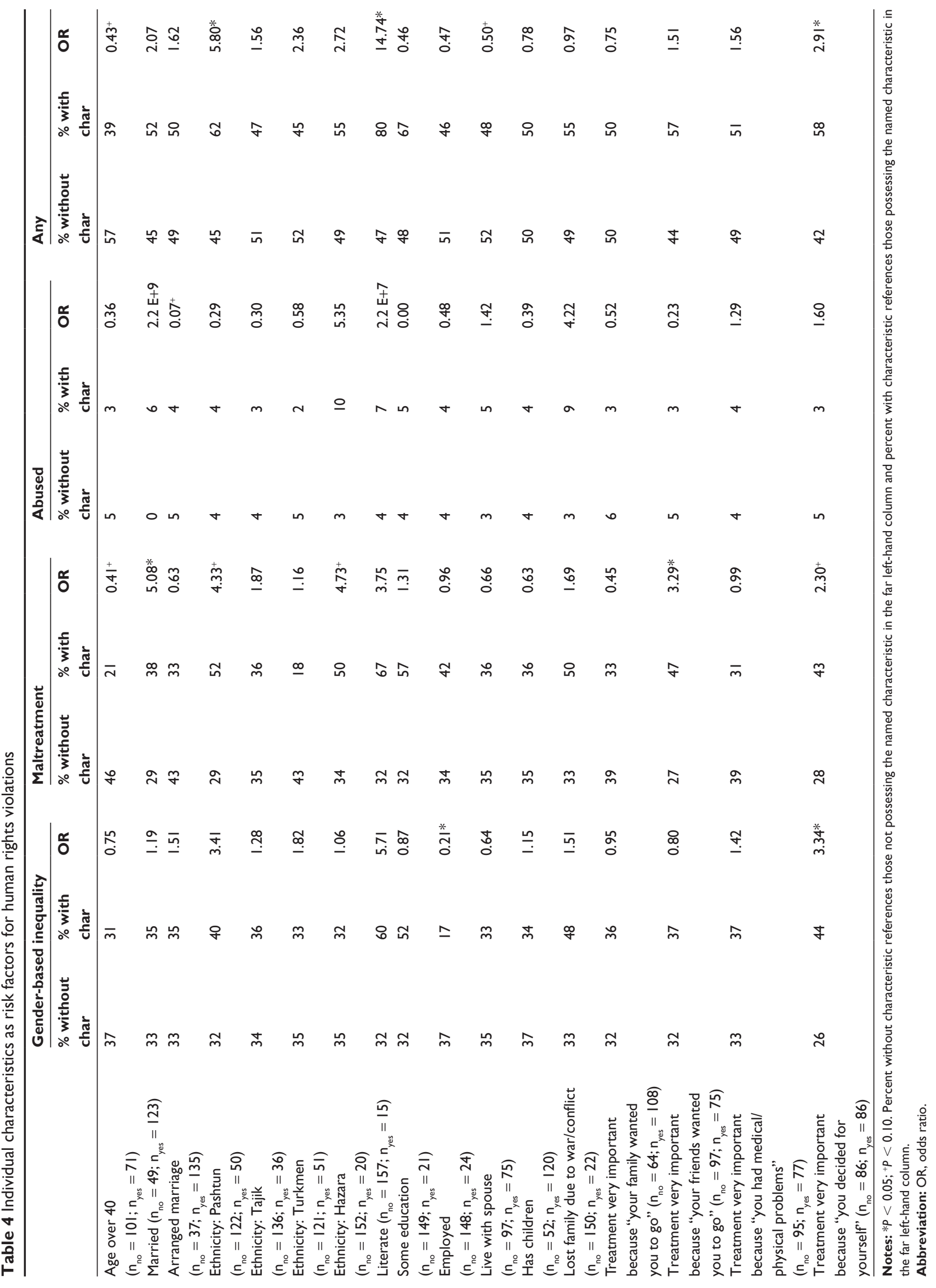


Table 5 Mental health risk factors for human rights violations

\begin{tabular}{lllll}
\hline & $\begin{array}{l}\text { Gender-based } \\
\text { inequality }\end{array}$ & Maltreatment & Abused & Any \\
\hline $\mathrm{n}$ & $\mathrm{I} 7 \mathrm{I}$ & 172 & 172 & 172 \\
Social functioning & 1.22 & $2.36^{*}$ & $12.24^{*}$ & $1.72^{*}$ \\
Suicide ideation & 1.10 & 0.86 & 0.61 & 0.95 \\
Suicide attempt & $2.80^{+}$ & $5.74^{*}$ & $26.05^{*}$ & $3.99^{*}$ \\
\hline
\end{tabular}

Note: ${ }^{*} P<0.05 ;{ }^{+} P<0.10$

Women who entered treatment because of their own desire were more likely to have experienced gender-based inequality. Because these DAT centers offered women residential treatment, women may have seen the centers as an alternative form of shelter.

Women with limited social functioning were more likely to have experienced all forms of human rights violations except for gender-based inequality. Women who are mistreated and abused likely experience inadequate social functioning due to the restrictions placed on them by their spouses or family members, and possibly by the shame and terror they feel from experiencing such abuse. Although no significant relationships were found for women who had suicide ideation, women who had attempted suicide were more likely to report experiencing all forms of human rights violations. These findings emphasize that human rights violations have a severe impact on the mental health of Afghan women, and suggest that reducing such violations might also help reduce suicide attempts among these women. The results from this study related to the relationships between mental health and human rights violations are supported by Cardozo et al's research ${ }^{9}$ that indicates the most traumatic events reported by Afghan women were related to denial of human rights, and other research that shows that women experiencing these violations also report serious mental health problems. ${ }^{8}$

Several limitations of this study need to be addressed. First, this was not a generalizable sample of drug-addicted women in Afghanistan, but rather a purposive sample of women who entered three female DAT centers in Afghanistan, which were the only addiction services available for women at the time of this study. The majority of Afghan women live in rural areas, where little has changed for decades, and daily conditions are especially harsh in western Afghanistan., 3, 35 Because the women sampled had access to treatment, it could indicate that these women had greater means, resources, or support than other drug-addicted women in Afghanistan. Second, we have very low base rates for physical and sexual abuse in the human rights violations scale. Future research with this population needs to be conducted to help us better understand the prevalence of sexual and physical abuse as well as related attitudes around this issue. Third, we had small effect sizes for our results in general. However, we still feel that these results provide a first step toward better understanding the severe impact of human rights violations on Afghan women. Finally, due to the fact that research on the denial of women's human rights in Afghanistan is in its early stages, much work needs to be done with regard to scale development. For example, there is a lack of formative work determining what Afghan women (of various ages and ethnicity) perceive as violations to their rights versus moral or cultural expectations. Qualitative research could help enrich the results reported from this study and would better our understanding of the perceptions and impact of human rights violations among Afghan women.

\section{Conclusions and implications}

This study found that women entering DAT centers had experienced a high rate of human rights violations prior to entering the centers. To be effective, DAT centers need to add services that help female patients cope with the human rights violations they have experienced. Also, services should be provided that may help prevent future human rights violations. For example, this study showed that women who were employed were less likely to have experienced human rights violations. Therefore, offering educational classes and vocational skills training may provide Afghan women with opportunities that could prevent this type of abuse. It is important that treatment programming take into consideration the cultural and contextual factors of women living in a war-torn country where denial of women's basic human rights is the norm.

The study showed that female patients who reported coming to the DAT centers due to their own desire were also more likely to have experienced human rights violations prior to entering the centers. Further, patients who were married, literate, unemployed, or of Pashtun ethnicity were more likely to have experienced human rights violations. These individual characteristics should be used as a guide to identify patients at treatment entry who are most in need of special services that help women deal with human rights violations.

Significant relationships between mental health problems and human rights violations were also found, including limited social functioning and suicide attempts. More emphasis should be placed on helping women in treatment cope with their experiences of human rights violations which, in turn, may strengthen their mental health. Because women in the DAT centers in this study come from rural areas with minimal professional services for them to use after residential 
treatment, it is important that these specialized services be provided at the DAT centers.

This study found that many drug addicted women in Afghanistan who enter DAT have mental health problems. As such, many of the women in Afghan DAT programs suffer from co-occurring substance abuse and mental disorders. Understanding the importance of integrating treatment services for substance abuse and mental disorders is critical for Afghan residential DAT providers to assist their female patients in achieving effective and healthier lives. Further, despite its prevalence, few DAT programs assess, treat, or educate patients and/or staff about trauma. ${ }^{38}$ Failure to address this issue has serious consequences, including relapse, greater violence that leads to increased substance abuse, and higher rates of depression. ${ }^{39,40}$

Given the connection between spirituality and recovery from trauma such as the mental health problems found in this study, ${ }^{41}$ treatment approaches that include a spiritual component offer survivors an opportunity to explore and reestablish their own personal sense of spirituality as they reflect on the lessons learned from their trauma experience. Given the prominence of the Islamic faith in Afghan culture, incorporating spirituality into the counseling regimen of Afghan women's DAT programs represents a promising practice that could assist in their recovery from addiction and trauma.

In conclusion, more research about human rights violations and mental health problems among Afghan women is needed. Further, an evaluation of the recommended changes in Afghanistan DAT centers should be conducted in a larger study in order to determine the effectiveness of these services in increasing mental health and coping among Afghan women.

\section{Acknowledgments}

This research was supported by the US Department of State, Bureau for International Narcotics and Law Enforcement Affairs, through contract number: S-AQMPD-067-D0116. We would like to thank the staff of D3 Systems and Afghan Center for Socio-Economic and Opinion Research (ACSOR) for their assistance in instrument translation and data collection. We would also like to extend a special acknowledgement to the Afghan drug abuse treatment center directors and staff and to the participants in this study. Further we thank Dr Rick Offner for his insightful comments on an earlier version of this article.

\section{Disclosure}

The authors report no conflicts of interest in this work.

\section{References}

1. Abu-Lughod L. Do Muslim women really need saving? Anthropological reflections on cultural relativism and its others. Am Anthropol. 2002; 104(3):783-790.

2. Rostami-Povey E. Women in Afghanistan: passive victims of the borga or active social participants? Dev Prac. 2003;13(2-3):266-277.

3. Riphenburg CJ. Post-Taliban Afghanistan: changed outlook for women? Asian Surv. 2004;44(3):401-421.

4. Rostami-Povey E. Gender, agency, and identity, the case of Afghan women in Afghanistan, Pakistan, and Iran. J Dev Stud. 2007;43(2): 294-311.

5. US Department of State. 2010 Human rights report: Afghanistan. Bureau of democracy, human rights, and labor - 2010 country reports on human rights practices. 2011. Available from: http://www.state.gov/ documents/organization/160445.pdf. Accessed April 8, 2011.

6. Amowitz LL, Kim G, Reis C, Asher JL, Iacopino V. Human rights abuses and concerns about women's health and human rights in southern Iraq. JAMA. 2004;291(12):1471-1479.

7. Rasekh Z, Bauer HM, Manos MM, Lacopino V. Women's health and human rights in Afghanistan. JAMA. 1998;280(5):449-455.

8. Amowitz LL, Heisler M, Iacopino V. A population-based assessment of women's mental health and attitudes toward women's human rights in Afghanistan. J Womens Health (Larchmt). 2003;12(6):577-587.

9. Cardozo BL, Bilukha OO, Gotway CA, Wolfe MI, Gerber MI, Anderson M. Report from the CDC: mental health of women in postwar Afghanistan. J Womens Health (Larchmt). 2005;14(4): 285-293.

10. Brady KT, KilleenT, Saladin ME, Dansky B, Becker S. Comorbid substance abuse and posttraumatic stress disorder. Am J Addict. 1994; 3(2): 160-164.

11. Gerolamo AM. State of the science: women and the nonpharmacological treatment of substance abuse. J Am Psychiatr Nurses Assoc. 2004;10: 181-189.

12. United Nations Office on Drugs and Crime. Drug use in Afghanistan: 2009 survey - executive summary. 2009. Available from: http://www. unodc.org/documents/data-and-analysis/Studies/Afghan-Drug-Survey2009-Executive-Summary-web.pdf. Accessed November 15, 2010.

13. Afghanistan Independent Human Rights Commission: Research and Planning Section. Effective factors associated with drug addiction and the consequences of addiction among Afghan women. 2008. Available from: http://www.aihrc.org.af/2008/Mar/Rep_Afghan_women_Drug_ Abuse.pdf. Accessed November 15, 2010.

14. United Nations. The universal declaration of human rights. 2011. Available from: http://www.un.org/en/documents/udhr/. Accessed August 27, 2011.

15. Ayton-Shenker D. The challenge of human rights and cultural diversity. 1995. Available from: http://www.un.org/rights/dpi1627e.htm. Accessed August 27, 2011.

16. Shah N. The constitution of Afghanistan and womens rights. Feminist Legal Studies. 2005;13(2):239-258.

17. United Nations Office on Drugs and Crime. Afghanistan drug use survey 2005. 2005. Available from: http://www.unodc.org/pdf/afg/20 05AfghanistanDrugUseSurvey.pdf. Accessed November 15, 2010.

18. Brady TM, Ashley OS. Women in Substance Abuse Treatment: Results from the Alcohol and Drug Services Study (ADSS). Rockville, MD: Substance Abuse and Mental Health Services Administration, Office of Applied Studies; 2005.

19. Simons L, Ducette J, Kirby KC, Stahler G, Shipley TE Jr. Childhood trauma, avoidance coping, and alcohol and other drug use among women in residential and outpatient treatment programs. Alcohol Treat $Q$. 2003;21(4):37-54.

20. Maguet O, Majeed M. Implementing harm reduction for heroin users in Afghanistan, the worldwide opium supplier. Int J Drug Policy. 2010;21(2):119-121.

21. ABC News. Afghanistan and Iraq polls: "Where things stand". 2010. Available from: http://abcnews.go.com/PollingUnit/afghanistan-iraqpolls-things-stand/story?id=6627152. Accessed August 27, 2011. 
22. Feld K, Gardner V, Hashimi S. Living Female in Afghanistan. Vienna, VA: D3 Systems; 2010.

23. Pedhazur EJ, Schmelkin LP. Measurement, Design, and Analysis: An Integrated Approach. Hillsdale, NJ: Lawrence Erlbaum Associates; 1991.

24. Hays RD, Sherbourne CD, Mazel R. The RAND 36-Item Health Survey 1.0. Health Econ. 1993;2(3):217-227.

25. Lung FW, Lee MB. The five-item brief-symptom rating scale as a suicide ideation screening instrument for psychiatric inpatients and community residents. BMC Psychiatry. 2008;8:53.

26. Butler M. Canadian Women and the (Re)Production of Women in Afghanistan. Vancouver, BC: Political Science, The University of British Columbia; 2008

27. The Colombo Plan. Empowering recovering women in Afghanistan 2010. Available from: http://www.colombo-plan.org/viewNews Content.php?id=140\&page=4. Accessed July 27, 2011.

28. IRIN. Bitter-sweet harvest: Afghanistan's new war. 2004. Available from: http://irinnews.org/pdf/in-depth/Bitter-Sweet-Harvest-AfghanistansNew-War.pdf. Accessed July 27, 2011.

29. Human Rights Watch. "We Have the Promises of the World": Women's Rights in Afghanistan. New York, NY: Human Rights Watch; 2009.

30. United Nations Office on Drugs and Crime - Country Office for Afghanistan. Illicit drug trends in Afghanistan. 2008. Available from: http://www.unodc.org/documents/afghanistan//Opium_Surveys/Illicit_ Drug_Trends_Report_Afg_13_June_2008.pdf. Accessed November 12, 2010.

31. Turner H. Literature review: Afghanistan women's health crisis, health service delivery, and ethical issues for international aid. Health Care Women Int. 2006;27(8):748-759.

32. Filkins D. Afghan women protest new law on home life. New York Times (April 16, 2009). Available from: http://www.nytimes. com/2009/04/16/world/asia/16afghan.html?ref=women. Accessed July 27, 2011.
33. Lykes MB, Coquillon ED. Psychosocial trauma, poverty and human rights in communities. In: Fox D, Prilleltensky I, Austin S, editors. Critical Psychology. Los Angeles, CA: Sage Publications; 2009: 285-299.

34. World Health Organization. Suicide rates per 100,000 by country, year and sex. 2011. Available from: http://www.who.int/mental_health/ prevention/suicide_rates/en/. Accessed July 27, 2011.

35. Ahmed-Ghosh H. A History of women in Afghanistan: lessons learnt for the future or yesterday and tomorrow: women of Afghanistan. $J$ Int Womens Stud. 2003;4(3):1-14.

36. Maletta H. Gender and employment in rural Afghanistan, 2003-5. J Asian Afr Stud. 2008;43(2):173-196.

37. Afghanistan Women Council. Literacy and human rights project. 2011 Available from: http://www.afghanistanwomencouncil.org/product-3. htm. Accessed July 27, 2011.

38. Najavits LM, Rosier M, Nolan AL, Freeman MC. A new gender-based model for women's recovery from substance abuse: results of a pilot outcome study Am J Drug Alcohol Abuse. 2000;33(1):5-11.

39. US Department of State. Substance abuse treatment interventions for women with co-occurring disorders (COD). 2011. Available from: http://www.highbeam.com/doc/1G1-195982218.html. Accessed July 27, 2011.

40. US Department of State. Substance Abuse Interventions for Women Who Have Experienced Trauma: A Training Program for Addiction Specialists on Creating Gender-Responsive Substance Abuse Treatment Interventions. Washington, DC: US Department of State, Bureau for International Narcotics and Law Enforcement Affairs; 2011.

41. Taylor AJ. Spirituality and personal values: neglected components of trauma treatment. Traumatology. 2001;7(3):111-119.
International Journal of Women's Health

\section{Publish your work in this journal}

The International Journal of Women's Health is an international, peerreviewed open-access journal publishing original research, reports, reviews and commentaries on all aspects of women's healthcare including gynecology, obstetrics, and breast cancer. Subject areas include: Chronic conditions (migraine headaches, arthritis, osteoporosis);

\section{Dovepress}

Endocrine and autoimmune syndromes; Sexual and reproductive health; Psychological and psychosocial conditions. The manuscript management system is completely online and includes a very quick and fair peer-review system. Visit http://www.dovepress.com/ testimonials.php to read real quotes from published authors. 